\title{
Impediments to reform in the Australian Building and Construction Industry
}

Martin Loosemore, (Professor, Faculty of the Built Enviornment, University of New South Wales, Australia)

ABSTRACT

The Cole Royal Commission into the Construction and Building Industry has generated heated debate, making recommendations that go to the heart of established cultures, power structures and management practices. While the Cole Report had a difficult birth, the implementation of the reforms is likely to be more painful. Unlocking the untapped productive potential, which Cole argues exists, will depend upon addressing the many impediments to reform that exist in the construction and building industry. This paper explores these impediments, suggesting a number of strategies to overcome them at a project, company and government level. It concludes that unless there is a fundamental shift in the established power structures and relationships within the industry, change is likely to be hard won.

Keywords: Reform, Royal Commission, Productivity, Culture, Stakeholders.

\section{INTRODUCTION}

There are two main aspects to industry reform, namely 'the ability to generate innovative ideas' and 'the ability to implement them at industry and organisational level'. There is no evidence to suggest that the construction industry is any less creative than other industries. However, there is evidence to suggest that the industry struggles to achieve consistently high performance, relative to other industries, against significant institutional, organisational and cultural barriers, which have instilled a relatively high resistance to change (Maddock, 1989; RCBI, 1992; EDC, 1994; DPWS, 1998). Consequently, despite numerous reform agendas over the last twenty years, the impact of regulation has often been disappointing. The public's image of the Building and Construction Industry continues to be one that is difficult, confrontational, unreliable, dangerous and generally unattractive (RCBCl, 2002a).

This is an important problem because as international competition increases within the Building and Construction Industry, which has remained relatively domestic compared to other industries, an ability to pro-actively identify and implement reforms agendas will be essential to sustained competitiveness (Mawhinney, 2001). Furthermore, the activities of the Building and Construction Industry have a significant economic, social and environmental impact upon Australian Society. For example, it directly generates about five per cent of Australia's GDP; directly employs over 700000 people nationwide; contributes more than fifty per cent of landfill waste in Australia; and it produces a product in which the vast majority of Australians live, ninety-five per cent work and where over ninety per cent of the nation's GDP is generated (EPA, 1998; RCBCl, 2002a; $\mathrm{RCBCl}, 2002 \mathrm{~b})$.

The aim of this paper is to discuss the institutional, organisational and cultural impediments to reform in the Australian Building and Construction Industry by drawing upon recent research in this area and recent Royal Commission Discussion Papers. The objective is not to argue for or against reform or to consider what the tangible results of reform should be. Rather, it is to highlight issues that need addressing if resistance to change is to be reduced.

\section{INSTITUTIONALISED IMPEDIMENTS TO REFORM}

The Building and Construction Industry is complex, cluttered, fragmented and characterized by a broad range of disparate bodies with different and often conflicting interests and agendas. These interests are represented by over seventy overlapping employer and industry associations/ organizations with blurred lines of responsibilities and interests (RCBCl, 2002a). This structure is not conducive to reform since it is difficult for these competing bodies to come together and agree on a reform agenda and coordinate their activities in an effort to bring about meaningful change. The industry also lacks a central coordinating body that is accountable for reform, despite past calls for a Ministry of Construction by the last Royal Commission into Productivity in the Building Industry in NSW (RCBI, 1992).

The geographical and functional fragmentation of the industry's representative bodies is reflected in the complexity of regulations that control the industry. Although the dominant approach in Australia has been one of selfregulation, the effectiveness of past regulation has been questionable and critics of the industry have voiced specific concerns over its regulatory framework such as a lack of commonality between states and territories. It has been argued that this prevents potential efficiency benefits that can be gained from a borderless market (RCBCl, 2002a).

Institutional barriers to reform also arise from the negative public image of the Australian Building and Construction Industry. This in turn, influences relative investment levels in the industry that could be used to fund innovation. While past reforms may have had some impact, it is also critically important that they have a perceived impact in the wider community. If the industry is perceived to have low rates 
of pay, to be low-tech and dangerous then it will not attract the monetary investments and talent that is required to drive future reform and to ensure that current reforms are implemented effectively. Ultimately, the impact of reforms is dependent upon the skills and abilities of those in the industry that have to bring them about.

Another institution that plays an important role in industry reform is the Union. Few would argue that unions have an obvious and important role to play in any industry reform agenda and Discussion Paper 1 (RCBCl, 2002a) implies a social responsibility to involve them in regulatory reform. However, perceptions vary about whether their role is positive or not. For example, some argue that the relatively difficult and often openly aggressive employer/ union relations in the Australian Building and Construction Industry have been a major impediment to reform (Garling, 1991; RCBCl, 2002a; RCBCl, 2002e). Conversely, others argue that Union activities have had a positive impact on industry reform over the years by exposing the practices of unscrupulous employers that place workers' health, safety and well-being at risk (Ferguson, 1999). There are clearly merits in each argument, but whatever position is taken Unions undoubtedly have an important role to play in the reform process because they influence many of the people who will be depended upon to implement reform at operational level.

\section{CULTURAL IMPEDIMENTS TO REFORM}

Culture refers to the shared values and beliefs, which shape the way that people communicate and work. Culture is reflected in people's attitudes and evidence indicates that they are largely sceptical towards innovation in the Building and Construction Industry and see it as someone else's responsibility (Lenard, 1996). For example, Loosemore et al. (2002) found a widespread belief amongst consultants and contractors that the primary responsibility for both product and process innovation lay with sub-contractors and manufacturers respectively (Loosemore et al., 2002). Subcontractors increasingly take the risks of performance and are perceived to have the expertise and knowledge to make potential improvements in their specialist areas of expertise. Principal contractors can only coordinate and manage these innovations to ensure that an overall project was delivered on time and within budget. This contrasts with the findings of Lamborde and Sanvido (1994) who found that process innovations were in the control and responsibility of main contractors, although it is unclear whether the companies in their sample were management contractors or traditional contractors. Loosemore et al.'s findings suggest that the trend for contractors to off-load their traditional construction responsibilities in favour of a coordinating role might be accompanied by a risk of confusion over the responsibility for process innovation.

This trend is worrying since reform is a long-term, continuous process that requires considerable investments of resources with no immediate prospect of returns.
Ironically, while smaller firms may have a more conducive culture and structure to innovation, most operate in the short-term and due to high gearing and relatively low margins, do not have the support of sufficient resources to make such long-term investments. Furthermore, they are highly sensitive to the workload fluctuations that act as a further disincentive to long-term investment in reform (Tatum, 1986). In contrast, larger companies have the necessary resources, financial stability and capacity to benefit from long-term investments but are less likely to have conducive structures and cultures (White et al., 1988; Skibniewki and Chao, 1992). As Lamborde and Sandvido (1994) found, there is no evidence to indicate that company size is in itself a barrier to innovation. Loosemore et al.'s research indicates that the dilemma facing the construction industry is that principal contractors with the resources to innovate are unwilling and technologically less able to do so and that the sub-contractors who are capable and willing to do so, do not have the necessary resources. It would seem that the problem of innovation is primarily one of resource distribution and attitudes rather than of complacency. This is ironic, since Seaden (1996) argues that costs could be reduced by up to fifty per cent from investing a knowledge enhancing activities. Clearly, what is needed to break the under-resourcing cycle is a system that enables subcontractors to benefit from the potential savings of their innovations.

Given the above, it is not surprising that few organizations have consistent research and development policies and those policies that do exist play little role in the strategic planning process. In general, innovation is perceived as an academic activity, which in most instances produces theoretical results of little commercial value (Loosemore et al., 2002). The perception is that relatively few new ideas furnish commensurate benefits and that they produce unsatisfactory rates-of-return and few improvements in competitiveness. Loosemore et al. (2002a) argues that this negative attitude is related to the masculine culture of the industry that has a tradition of physical activities and an emphasis on production, which cannot be learnt effectively in a classroom environment. Furthermore, many employees of the Building and Construction Industry have been failed by the traditional classroom-based educational system and perceive learning as a non-productive, feminine activity and associate it with failure. This is a major cultural barrier to education, training and ultimately reform, which permeates every level of the industry.

Whatever the reasons for the industry's negative attitudes, they are worrying because positive attitudes towards innovation are the most fundamental building block of reform (Dumbelton, 1986; Toole, 1998). Dumbelton (1986) argued that the way to tackle this problem is to redress the often tense relationship that exists between academia and practice. Dumbelton found that innovative organizations closely integrate the activities of external research 
institutions into their activities, making their research and development function equal in status with other production functions and an integral aspect of company culture. This can be achieved through strategic partnerships with universities or as Kangari and Miyatake (1997) suggest, through strategic alliances with high technology firms in other industries. This is the approach which is favoured by Singaporean and Japanese construction companies and which is encouraged by their respective governments.

\section{ORGANIZATIONAL IMPEDIMENTS TO REFORM}

Significant impediments to reform can be found in the traditional way in which the industry organises and manages its projects.

\section{Clients}

Clients of the Building and Construction Industry play an extremely important role in the reform process, through their expectations of performance, purchasing power and their ability to develop codes of practice and other legislation that impacts upon work arrangements in the industry (RCBCl, 2002a; RCBCl, 2002b). However, Loosemore et al. (2002) found a widespread perception that the majority of construction clients place a low value upon new ideas. Most construction innovations appear to emerge from having to cope with the complex and challenging production environment of the industry, than in response to specific client requirements. That is, they appear to be productionled rather than client-led, being reactive rather than proactive and arising out of adversity rather than a market led desire for performance optimisation in a competitive environment. Indeed, this finding is reflected in the many reforms reports that have punctuated the industry's past, that have largely been instigated reactively by government or private clients, in response to problems within the industry.

It is clear that both private and public clients have an important role to drive reform in the Australian Building and Construction Industry, although their relative contributions differ from sector-to-sector. For example, RCBCl (2002a) shows that the building sector is dominated by private clients while the engineering sector is dominated by public clients. In the public sector, the Commonwealth Government undertook forty-one per cent, the states and territories forty per cent and local governments nineteen per cent. Since the engineering sector is considerably larger than the building sector, there is a multiplier effect of public sector investment, which means that they have a relatively larger impact on overall reform than private clients.

\section{Competition}

Another way in which clients inhibit innovation is through their employment practices that determine cost and time pressures and ultimately, the resources available to invest in research and development. In particular, when competitive tendering is used with the primary objective of securing the lowest price, there will be insufficient resources or motivation to seek innovative solutions to clients' needs. This potential problem is referred to in $\mathrm{RCBCl}$ (2002a: 30 ), which intimates that severe resource constraints have been a cause of problems in the industry - 'the tight profit margins in the industry have led to head contractors seeking avenues to reduce risks wherever possible'. Unfortunately, with a general ignorance of good risk management practices in the industry, the common coping strategy is to pass these risks down the contractual chain to parties who do not have the capacity to manage them effectively. To often, the result is that the client suffers a delayed project or higher price. As Nam and Tatum (1997) found, innovation is contingent upon access to slack resources and an attitude towards investment rather than cost cutting. In this sense, alternative procurement methods such as partnering, which place less emphasis on price as the sole employment criterion, would seem to benefit reform and innovation in the industry. However, it is also interesting to note that many contemporary management techniques finding popularity in the Australian Building and Construction Industry, such as lean construction and business process reengineering, which seek to reduce redundancy and waste in organizations, can be damaging to innovation (Green, 1999; Loosemore, 2000). Yet ironically, they are often sold on the basis that they will increase innovation.

The idea that competition can be a disincentive to reform is interesting because competitive forces are often quoted as the driving-force behind innovation (Dumbleton, 1986; Tatum 1987). Indeed, this latter argument is reflected in $\mathrm{RCBCl}$ (2002c), which argues that increased competition and resource pressures, forces the Australian Building and Construction Industry to think of ways to do things more effectively. RCBCl (2002c) argues that there is virtually no international competition, few alternative products and significant barriers to entry into the industry. This is a problem because new players are likely to be more innovative and there is little pressure on individual employers to break ranks and run the risk of trying to change the way the industry works. It also argues that more rigorous pre-qualification can act as a barrier to entry for new firms wanting to gain work in the construction industry.

While there is some truth in this argument, there is undoubtedly a point at which an over-emphasis on price and excessive competition becomes destructive. The key point is that competitive tendering must not be abused to the point where margins are eroded to restrictively low levels, thereby reducing the incentive and resources available for innovation (Garling, 1991; Gann, 1997). Too often, contractors and consultants in the Australian Building and Construction industry, place themselves at a competitive disadvantage to those who focus upon price. The danger is that this forces the performance of the industry down to the lowest common denominator. Furthermore, excessive competition 
can impede the development of partnerships, networks and alliances to undertake research and development (BIE 1986). When competition is extreme, the tendency is for construction companies to use contractual practices to offload the risk of innovation to sub-contractors and suppliers. In many instances, these organizations are not aware of the risks they are taking on and are not best placed to manage them. The result is a selfish, confrontational and uncooperative environment, whereas what is needed for innovation is a trusting, open, risk-sharing environment, which fosters cooperation (Johnson and Tatum, 1993).

Broader pre-qualification is a useful method of ensuring that competition does not become destructive. Indeed, this has occurred in the UK where there is currently strong reform agenda away from competition as a driver for innovation towards a more humanistic approach based of long-term partnering, mutual confidence, respect for people and trust where there is not so much emphasis on price, particularly in the public sector. This is encapsulated in the principles underpinning the UK's client-led Movement for Innovation (M4i), the main mechanism by which the UK government is implementing its ambitious reform agenda that was catalyzed by a long-standing client dissatisfaction with the construction industry.

\section{Methods of procurement}

Many construction companies, particularly in the major projects sector, have attempted to overcome the problems of excessive competition by nurturing close and long-term relationships with clients (Nam and Tatum, 1992). These arrangements, referred to as Partnering or Strategic Alliances, were recommended as an alternative method of procurement by the Gyles Commission and CIDA in the early 1990s, as a means for clients to achieve better value for money (RCBCl, 2002a: 27). The intention is to eliminate competition and to facilitate trusting relationships which in turn lead to a more consistent work-stream underpinned by more realistic resource levels, project development periods and more open, flexible, responsive and equitable procurement and contractual practices. As Nam and Tatum (1997) found, a high level of owner participation fosters innovation particularly when where there is a long-term relationship with designers and contractors. While $\mathrm{RCBCl}$ (2002c) suggests this may stifle innovation by increasing barriers to entry within the industry, Nam and Tatum argue that this creates a stable and predictable environment of collective responsibility, where there is a reduced risk of failure and where parties have the time to cultivate relationships and develop flexibility, understanding and confidence to initiate new ideas with the certainty of being able to benefit from them.
Unfortunately, the majority of construction clients are unsophisticated, procure buildings infrequently and find it difficult to see any direct benefit from reducing their emphasis upon price. This is the economic dilemma of reform in the construction industry. The potential for investments in innovation is restricted to the relatively few large companies who are lucky enough to deal with sophisticated and relatively wealthy clients who procure buildings on a frequent basis.

An alternative solution to forming alliances with clients is to do so with competitors to develop new ideas from which both can benefit (Johnson and Tatum, 1993). An advantage of this strategy is that the risks of innovation are also shared. However, Loosemore et al. (2002) found a strong view that competition in the Australian Building and Construction Industry will increasingly mean working against, rather than with one's competitors and the idea of inter-firm cooperation to spread the risk of innovations would only occur on mega-projects which were beyond the capacity of individual companies. Furthermore, $\mathrm{RCBCl}$ (2002c) argued that alliances and mergers could increase barriers to entry within the industry and reduce competition to the extent that there is virtually a monopoly situation and little incentive to innovative.

\section{The project-based nature of construction}

Another barrier to inter-firm cooperation is the project-based nature of construction activity which often creates the perception that innovations also have to be project-specific (Loosemore et al., 2002). Most projects are operated as competitive cost-centres and, their temporary nature means that long-term investments in innovation are unlikely to furnish returns in time for those who invested in them. Loosemore et al. also found a strong perception that the lack of standardisation across projects provided little scope for transferable innovations. Furthermore, the increasingly tight time-scales and resource constraints being imposed upon contractors provided little opportunity to innovate or to form innovation alliances. Consequently, the little innovation that takes place does so in a reactive rather than proactive way. This runs contrary to Johnson and Tatum's (1993) research that found that sustainable innovation needs structuring and planning.

\section{Long supply chains}

There is a significant amount of literature that indicates that the supply chain created by the traditional building procurement process is long and unwieldy and that the communication problems that result are a major disincentive to reform. For example, Tatum (1987a) and Lamborde and Sanvido (1994) have argued that long supply chains are a 
the final product into which their new technology or service is incorporated. For example, a domestic sub-contractor's lack of involvement in design means that any technological innovations must be offered through a principal contractor who is likely to filter the potential benefits to the innovating sub-contractor. Another problem with long supply chains is a lack of integration in the benefits gained from innovation from its various members (Slaughter 1983). For example, builders' benefits are project-specific, while manufacturers' benefits are product-specific. This introduces the dilemma that while builders are best placed to identify innovations, material/product manufacturers have little incentive to respond in a time-frame which enables builders to benefit from them. Indeed, because the client base of manufacturers is fragmented, they have little incentive to innovate at all and the result is a damaging stalemate in reform.

To some extent, alternative procurement systems such as design and build, management contracting and construction management reduce this problem by moving project participants closer to the end product. However, their impact is often limited by onerous, restrictive, divisive and unimaginative contracts, which provide a disincentive to innovate and which focus upon the detection of problems rather than opportunities (Loosemore 1998). Not only do the majority of construction contracts impose no obligation to suggest improvements to working practices, they make no provision for innovators to work together in developing new ideas or to share in any benefits that may accrue from them.

\section{CONCLUSION}

This paper has discussed the main impediments to reform in the Australian Building and Construction Industry. It has shown that an effective reform process will require changes in the way that construction projects and construction companies are managed and in the way that the government-industry interface is managed.

At project level, changes should include:

- More direct lines of communication between innovators and construction clients;

- Shorter supply chains;

- Reduced emphasis upon price as a sole employment criteria;

- More emphasis upon negotiation rather than competition;

- More equitable, risk-sharing contracts;

- More realistic resourcing of projects;

- Building in redundancy and slack resources;

- Being cautious of modern management fads;

- Providing better opportunities for innovators to benefit from their ideas; and

- Setting in place structures and plans to better integrate managerial, research and technical knowledge.

At company level, changes should include:
- The integration of research and development functions into mainstream business functions via short-term partnerships with compatible and effective research institutions and long-term investments in research and development departments;

- The development of a proactive, future orientated and participative culture which values and encourages new ideas and which does not penalise failure;

- The development of a flexible and decentralised structure which is not dominated by restrictive rules and procedures;

- A willingness to work with competitors for mutual benefit rather than to work against them;

- Effective internal communication between research, production and marketing functions;

- Imaginative and effective training;

- An understanding of market forces and an ability to predict future trends;

- Effective leadership in promoting the importance and benefits of innovation in increasing market share;

- An educated and courageous client-base; and

- Continuous, trusting and confident relationships with clients.

Finally, governments can also play a role in stimulating reform by assisting innovation in the private sector and ensuring the spread of ideas between and within different industries; by ensuring that companies can fully appropriate the benefits of private research and development; by providing back-up resources to firms who do not have the resources to invest in research and development and by facilitating networks and alliances between organizations and research institutions. The current low level of interaction between the government and the construction industry threatens the effective transfer of responsibility to the private sector.

To conclude, it is clear that the adoption of many of the above recommendations will require a fundamental mindset shift within the construction industry. The construction industry is unsophisticated compared to other industries, particularly in the High-Tech sector from which many lessons can be learnt. Unlike construction, they have embraced innovation as a key concept of culture and by doing so, have created their own creative momentum. Quality rather than price is the driving-force in these industries that have a vitality and positive image that is the envy of construction.

REFERENCES

AFCC (1998). Strategies for the Reduction of Claims and Disputes in the Construction Industry - a Research Report. Australian Federation of Construction Contractors.

APCC (1997). Construct Australia: Building a Better Construction Industry in Australia. Australian Procurement and Construction Council, Perth, APCC. 
Argyris, C. (1970). Organization and innovation. Richard D Irwin Inc, USA.

Australian Bureau of Statistics (ABS) (1998). Research and experimental development: Business Enterprises. ABS, Canberra.

Barda, P. (1995). In Principle. Australian Government Publishing Service, Canberra.

Bureau of Industry Economics (BIE) (1985). The public interest IR\&D program: Program evaluation report 1. AGPS, Canberra.

Bureau of Industry Economics (BIE) (1986). The public interest IR\&D program: Program evaluation report 2. AGPS, Canberra.

CIDA (1995). Measuring Up or Muddling Through: Best Practice in the Australian Non-Residential Construction Industry. Construction Industry Development Agency, Melbourne.

CIDA (1992). Business Plan. Construction Industry Development Agency, Melbourne.

Construction Industry Council (CIC) (1993). Profit from innovation. HMSO, London.

Construction Industry Development Agency (CIDA) (1995). A construction Industry Innovation strategy. AGPS, Canberra.

Construction Industry Institute (CII) (1996). Innovation: The key to competitive advantage, Research Report Number 9. Cll, Adelaide.

Cooke, I. and Mayes, P. (1996). Introduction to innovation and technology transfer. Artech House, Inc. Massachusetts.

CPSC (1996a). Code of Practice for the Construction Industry. NSW Government.

CPSC (1996b). Code of Tendering for the Construction Industry. NSW Government.

Davenport, D. (1994). Assessing the efficiency of international procurement systems in order to improve client satisfaction with construction investment - The French experience. In Rowlinson, S. (ed.) East meets West. Procurement Systems Symposium, CIB Publication 175, University of Hong Kong, Hong Kong, 43-51.

De-Valence, G. (1997). Construction Industry reform strategies in Australia: CIDA and the CPSC. First International Conference on Construction Industry Development, National University of Singapore, Singaporre, Vol 1, 124-131.

De-Valence, G. (1999). Australian Construction Industry Policy and process Re-engineering. Second International Conference on Construction process Re-engineering, University of NSW, Sydney, 241-252.
Department of Industry, Science and Tourism (DIST) (1998). Business expenditure of research and development - Industry characteristics, DIST, Sydney.

DIR (1989). Review of the Structural Efficiency Principle.

February-May, Department of Industrial Relations,

Commonwealth Government, Australian Government

Publishing Service, Canberra.

DISR (1999). Building for Growth. Department of Industry, Science and Resources, Canberra.

DITAC (1989). Indicative Survey of Non-Residential Construction Industry Efficiency. Department of Industry, Technology and Commerce, Canberra.

DPWS (1996). Capital Project Procurement Manual. NSW Departent of Public Works and Services, Sydney.

DPWS (1996). NSW Government Green Paper: The Construction Industry in NSW: Opportunities and Challenges. NSW Department of Public Works and Services, Sydney.

DPWS (1996a). NSW Government Green Paper: Security of payment in the construction industry. NSW Department of Public Works and Services, Sydney.

DPWS (1997). A Perspective on the Construction Industry in NSW. NSW Deparment of Public Works and Services, NSW, Sydney.

DPWS (1998). Construct NSW. NSW Department of Public Works and Services, NSW, Sydney.

Dumbelton, J. H. (1986). Management of high technology research and development. Elsevier Science Publishing Company, Netherlands.

EDC (1994). Inquiry into the Victorian Building and Construction Industry, Third Report to Parliament: Productivity, April, Economic Development Committee, Melbourne.

EPA (1998). Construction and demolition waste action plan. Environmental Protection Agency, Sydney.

Ferguson, A. (1999). More or less regulation of Safety? A Trade Unions perspective. In 1999 Construction Conference Business program, Sydney Hilton, 9-11 May, Sydney.

Furze, D. and Gale, C. (1996). Interpreting management - exploring change and complexity. International Thompson Business Press, London.

Garling, P. (1991). Research and development - preparing for the next building boom: The project deliverer's view. Building Science Forum of Australia, August, Sydney.

Gibson, J. E. (1981). Managing research and development. John Wiley and Sons, Inc., New York 
Green, S. D. (1999a). The missing arguments of Lean construction. Construction management and Economics, 17, 133-137.

IC (1991). Construction Costs of Major Projects. Industry Commission, AGPS, Canberra.

Johnson and Tatum, C. B. (1993). Technology in marine construction firms. ASCE Journal of Construction Engineering and Management, 119 (1), 148-162.

Kangari, R. and Miyatake, Y. (1997). Developing and managing innovative construction technologies in Japan. ASCE Journal of Construction Engineering and Management, 123 (1), 72-78.

Kerin, J. and Cook, P. (1989). Research, innovation and competitiveness. AGPS, Canberra.

Kumeraswamy (1994). New paradigms for research protocols. In Rowlinson, S. (ed.) East meets West. Procurement Systems Symposium, CIB Publication 175, University of Hong Kong, 143-149.

Lamborde, M. and Sanvido, V. (1994). Introducing new technologies into construction companies. ASCE Journal of Construction Engineering and Management, 120 (3), 334-345.

Lansley, P. (1997). The impact of BRE's commercialisation on the research community. Building Research and Information, 25 (5) 301-311.

Latham, M. (1994). Constructing the team. HMSO, London. Lemer, A. C. (1992). Construction research for the 21st Century. Building Research and Information, 20 (1), 28-34.

Lenard, D. J. (1996). Innovation and industrial culture in the Australian construction industry: A comparative benchmarking analysis of critical cultural indices underpinning innovation. Unpublished PhD Thesis, University of Newcastle, Newcastle.

Loosemore, M. (2000). Innovation - a note of caution. In Best, R. and De Valance, G. (eds) Building in value. Arnold, London.

Loosemore M., Choo H. and Koh J. (2002). Encouraging R\&D in construction. ASCE Journal of Professional Issues in Engineering Education and Practice, 128 (1), 25-30.

Loosemore M., Dainty, A. and Lingard, H. (2002a). Strategic human resource management in the construction industry Taylor and Francis, London.

Maddock Report (1989). The Predictability of Australian Project Performance. Department of Industry, Technology and Resources, Melbourne.

Mawhinney, M. (2001). International construction. Blackwell Science, Oxford.
Miyatake, Y. and Kangari, R. (1993). Experiencing computer integrated construction. ASCE Journal of Construction Engineering and Management, 19 (2).

Nam, C. N. and Tatum, C. B. (1992). 'Strategies for technology push - Lessons from construction innovations'. ASCE Journal of Construction Engineering and Management, 18 (3).

Nam, C. N. and Tatum, C. B. (1997). Leaders and champions for construction innovation. Construction Management and Economics, 15 (3), 259-270.

NatBACC (1999.) A report for government by the National Building and Construction Committee. National Building and Construction Committee,

NEDO (1983). Faster Building for industry. HMSO, London. NPWC (1990). No Dispute: Strategies for Improvement in the Australian Building and Construction Industry. National Public Works Council.

Pascale, R T (1991) Managing on the edge, Penguin Books, Harmondsworth.

Preece, C. N., Moodley, K. and Smith, A. M. (1998). Corporate communications in construction. Blackwell Science, Oxford.

RCBI (1992). Final Report by RV Gyles QC, Vols. 1-10. Royal Commission into Productivity in the Building Industry in NSW, Sydney.

RCBI (1991a). Productivity and the Australian Construction Industry. Royal Commission into Productivity in the Building Industry in NSW, Sydney.

RCBI (1991b). Contracts, Claims and Disputes: Toward Implementation of Existing Proposals. Royal Commission into Productivity in the Building Industry in NSW, Sydney.

$\mathrm{RCBCl}$ (2002a). Overview of the nature and operation of the Building and Construction Industry. Royal Commission into The Building and Construction Industry, Melbourne.

RCBCl (2002b). Statistical Compendium for the Building and Construction Industry. Royal Commission into The Building and Construction Industry, Melbourne.

$\mathrm{RCBCl}(2002 \mathrm{c})$. Productivity and performance in the Building and Construction Industry. Royal Commission into The Building and Construction Industry, Melbourne.

$\mathrm{RCBCl}$ (2002e). Key features and trends in Building and Construction Industry Enterprise Agreements. Royal Commission into The Building and Construction Industry, Melbourne.

Richardson, B. (1996). Modern management's role in the demise of a sustainable society. Journal of Contingencies and Crisis Management, 4 (1), 20-32. 
Roussel, P. A., Saad, K. N. and Erickson, T. J. (1991). Third generation R\&D: Managing the link to corporate strategy. Arthur D Little Inc, Massachussets.

Seaden, G. (1997). The future of national construction research organizations. Building Research and Information, 25 (5), 250-256.

Seaden, G. (1996). Economics of innovation in the construction industry. Journal of Infrastructure Systems, 2 (3), 103-107.

Skibniewki, M. J. and Chao, L. C. (1992). Evaluation of advanced construction technology with AHP method. ASCE Journal of Construction Engineering and Management, 118 (3), 289-301.

Slaughter, S. (1983). Builders as a source of construction innovation. ASCE Journal of Construction Engineering and Management, 119 (3), 532-549.

Tatum, C. B. (1987). Potential mechanisms for construction innovation. ASCE Journal of Construction Engineering and Management, 112 (2), 321-336.

Tatum, C. B. (1987a). Process of innovation in construction firms. ASCE Journal of Construction Engineering and Management, 113 (4), 648-663.

Toole, M. (1998). Uncertainty and home builders' adoption of technological innovations. ASCE Journal of Construction Engineering and Management, 124 (4), 323-332.

Uno, K. (1984). Recent trends in R\&D and patents - A quantitative appraisal. In Eto, H. and Matsui, K. (eds) Management systems in Japanese industry. Elsevier Science Publishers Ltd, Netherlands.

Ventre, F. (1979). Innovation in residential construction. Technological Revolution, 82 (2), 50-59.

White, M., Braczyk, J., Ghobadian, A. and Niebuhr, J. (1988). Small firms' innovation. PSI Research Report 690, Bourne Offset Ltd, London.

Wilson, A. H. (1986). How much for building research? Building Research and Practice, 14 (4), 235-238. 